\title{
Study the effect of emotional intelligence on organizational learning staff, Case study: Jihad Agriculture Organization of Isfahan
}

\author{
Bahman Saeidipour $^{\mathrm{a}^{*}}$, Peyman Akbari ${ }^{\mathrm{b}}$ and Mohammad Amin Marati Fashi ${ }^{\mathrm{c}}$
}

${ }^{a}$ Department of Educational Sciences, Payame Noor University, I. R. of IRAN

${ }^{b}$ Department of Management, Payame Noor University, I. R. of IRAN

'Student of Government Management, Islamic Azad University Naragh Branch, Naragh, Iran

A R T I C L I N F O AB S T R A T

\begin{tabular}{l}
\hline Article history: \\
Received April 20, 2012 \\
Accepted 21 July 2012 \\
Available online \\
July 222012 \\
\hline Keywords: \\
Intelligence \\
Emotional intelligence \\
Organizational learning
\end{tabular}

\section{Introduction}

These days, knowledge-based economy has become the most important parts of organizations and human resources are the most important components of firms. Indeed, human capital is the most critical strategic element and the most fundamental way to increase organizational effectiveness and efficiency and human capital will produce development of society. Committed human resources to the organization's goals and values, not only is a factor for the excellence of an organization to another organization, but also it is considered sustainable competitive advantage for many organizations (Rezayian \& Koshthgar, 2008). The primary goal of any organization to achieve the highest possible level of productivity or efficiency is to optimize processes (Jahanian, 2010). Several factors affect performance of individuals in the organization and emotional intelligence is one of the significant ones, which affects the organizational behavior. Emotional intelligence of Mayer \&

* Corresponding author.

E-mail addresses: bahmansaeidipour2012@gmail.com (B. Saeidipour)

(c) 2012 Growing Science Ltd. All rights reserved.

doi: 10.5267/j.msl.2012.07.015 
Solovey, is not only a positive characteristics, but also is a set of distinct discursive and emotional capabilities, and toward the social intelligence has more attention to fundamental issues of emotional and quell social and personal problems. People with high emotional intelligence in having a more satisfying life, enjoyment of family environment and sharing the feelings of others are different than others and they are normal people, sociable, successful, motivated and optimistic (Ostvar, 2008). BarOn (2000) believes that emotional intelligence, often, grows and it can be expanded for different purposes such as education, planning and treatment. He believes, people who have high emotional intelligence, generally deal with demands and environmental pressures are more successful performance (Beyrami et al, 2009).

Emotional intelligence is inherently attractive. Everyone agrees that having the skills of urban life and social information is more useful. People who can manage well recognize others' emotions, control their emotions and social interactions in the business world are one step ahead of others. For example, partners of an international consulting firm may have more emotional intelligence than average people do and compared to the other partners they earn 1.2 million dollars more income than other partners do (Robbins \& Judge, 2010). In today organizations, where working groups for getting success is an absolute necessity, managers, employees are the spirit of group's efforts, and empowerment of workplace with improved features can enhance the emotional intelligence. Leadership of an organization for adaptability with change and to survive and grow at new business environment requires special characteristics that generally managers to answer them are faced with many problems. In this field, the most important component of personality that could help leaders and managers is emotional intelligence. Considering the emotional intelligence is the power to use of feeling and emotion of self and others on individual and group behavior in order to achieve maximum utility. Therefore, integrating knowledge management and emotional skills in management can be effective and useful to propel people towards the goal. Understanding effective management of emotional intelligence not only provides new insights on how to motivate people, but also it provides more about emotions, and manages them, constructively (Feizi \& Abedini, 2010).

On the other hand, in every organization there is a potential that this strategic changes in organizations can use the massive power on optimal manner, and the ability be directed in line of organizational goals and vision. Motivating human resources to change is an essential necessary and it can create through the interaction among organizational structures. Thus, the organizational hierarchy, individuals and organizational groups in the organizational learning process can create appropriate links to increase organizational performance (Nazem, 2008). The new organizations have the capabilities for organizational learning (Mohrman et al, 1998). Peter Senge believes that only source of sustainable competitive advantage in the long term for organizations is to learn faster than competitors, which help them be more effective and efficient (Senge, 1999). Organizational learning occurs when each member realizes the difference between optimal and present results and tries to resolve problems. So today, conventional techniques and scientific management cannot take advantage of the capabilities of staff. Effective use of staff is necessary and organizational leadership need to be equipped with necessary skills. One of these skills is emotional intelligence and through emotional intelligence it is possible to capture the heart and soul of the organization members (Soltani, 2008). The main purpose of this study is to study the impact of emotional intelligence on organizational learning staff of Jihad Agriculture Organization of Isfahan.

\section{Theoretical Foundations and Literature review}

\subsection{Intelligence}

Intelligence as a basic feature, which could make a difference among human resources and it has been considered in various fields. For example, biologists have considered intelligence as an adaptation and survival factor. Philosophers have considered intelligence and education professionals have 
focused on learning ability. Intelligence refers to the general talent that encompasses all mental activity and helps human solve life problems (Gharibi Varzaqani, 2011). Wexler believes that intelligence, learning capacity and adaptive are related with environmental conditions and situations (Perkhaefi \& et al, 2010). If the brain simulates a factory, consider the mind into factory space and the intelligence, its product line. It is obvious whenever factory space is larger, if its product line expanded, more products is produced. In the intelligence, experience plays an important role (Ghassemzadeh Debgi, 2007). Some psychologists believe that intelligence is a unique principle, but the others believe that intelligence is not a general and unique principle and be included diverse set of capabilities. This psychologists suggest the term multiple intelligences for example they are divided intelligence into categories such as mathematical intelligence, social intelligence, literary intelligence, mystical intelligence, moral intelligence, cultural intelligence, emotional intelligence, etc. This research pays to study emotional intelligence.

\subsubsection{Emotional Intelligence}

Peter Solovey and John Mayer raised the concept of emotional intelligence for the first time in 1990 where they expressed emotional intelligence as a kind of emotional information processing, which includes proper evaluation of emotions and adaptive regulation of emotions (Nasrollahpour, 2007). Mayer \& Solovey (1997) defined emotional intelligence as capacity to cognitive, express, recognize, use, manage emotions in self and others which is included attention to feelings, clarity of feelings and reconstruction creation (Jahanian, 2011). According to Solovey and Mayer, emotional intelligence is a form of social intelligence, which represent the ability to control their emotions and others, and the difference among them and to guide them thought an appropriate action (Rezayian \& Keshthgar, 2008). Golmen believes that emotional intelligence includes both the internal and external elements. Internal elements include amount of consciousness, self concept, feelings of independence, capacity of self-actualization and decisiveness. An external element includes interpersonal relationship, facilitates empathy and feeling responsibility. Emotional intelligence also includes individual's capacity to accept realities, flexibility, ability to solve emotional problems, Ability to deal with stress and impulses (Golmen, 1995). Golmen (1995) believes that emotional intelligence had a positive impact on mental and physical health of staff and motivates progress. Some theorists believe that social and emotional intelligence are important and necessary for leaders and managers. Emotional intelligence skills allow people to think better under difficult conditions and to prevent wasting time due to feelings such as anger, anxiety and fear. People with high emotional intelligence have better abilities to prevent from anxiety and distress. Such people increase their cardiac and sincere attention than others do. Their minds become calm and clear quickly and easily, and thus open the way on themselves for intuition and insight and innovative ideas. Emotional intelligence reduces interpersonal problems by strengthening mental health, ability empathy with others, social adaptation, emotional well-being and life satisfaction and provides field of improving community relations (Besharat, 2005). Generally, people who are intelligence in terms of emotional characteristics are optimistic and have a trait, which enables them to focus on solutions instead of cause (of who is to blame). Since, work in any organization has its own problems and may lead to feelings of disillusionment and failure; people with high emotional intelligence know that organization is not responsible for all their unpleasant feelings (Rezayian \& Keshthgar, 2008).

\section{Emotional intelligence from the perspective of Weisinger}

Weisinger (2000 focused on study of emotional intelligence and defined intelligence as intelligent use of emotions and stated that people with high emotional intelligence use their emotions until they reach their goals. He points out that emotional intelligence can be developed, improved and increased and it does not a characteristic that people have or not. He has also expressed people can be strengthened their emotional intelligence with training and improve their skills and capabilities, which could increase emotional intelligence. 
He considers five components for measuring emotional intelligence, which are as follows,

1) Self-awareness: Awareness of people's emotions and behavior as other perception of people can affect somehow on their activities that act with their favor. The core of all the skills related to emotional intelligence is self-awareness. Self-awareness is a useful factor in emotional intelligence that helps people succeed.

2) Managing emotions: Emotions offers people many reasons to do the work well. Turning off emotions prevent people from the necessary information. Managing emotions means something that is exactly different from turning them off.

3) Spontaneous: A spontaneous employee requires less management and probably is more creative and more productive. According to Weisinger four sources of motivation are: Himself/herself, friends, family and colleagues, trusted friends and emotional and environment.

4) The good communication: Communications are based on all relationships. Effective communication helps us transfer our ideas more properly. In this kind of communication, people aware of their emotions and be sensitive to the emotions of others and pay attention them. According to Weisinger required skills for effective communication include: self- openness (means: a clear expression of something that the people thinks about that, feels and wants), courage (means, persistence and support their opinions and ideas while should be respected the opinions of others), effective listening (Listening to the words of others), Remonstrance and team communications.

5) Direction of emotions: The goal of direction emotions is to find useful communication with others. This means people engage in communication are synchronized and coordinated completely and they communicate, thoroughly. People with ability to direct high emotional can share their thoughts, feelings and ideas well and have the ability to listen well (Hedat, 2008). In the present study, to identify emotional intelligence of employees we use this model.

\section{2 organizational learning}

Today, learning is considered as an origin of earning points in commercial competition. The outstanding scholar of management believes that the key to organizational success is knowledge because the value is created through innovation and production and both depend on the application of knowledge. In other words, human equipped with knowledge is considered determinant and effective key in organization. Organizational learning is a dynamic process that enables organizations will adapt quickly with changes. The process includes generating new knowledge, skills and behaviors. Learning of organizational is the main way to create knowledge work and to improve the efficiency of organization. Therefore, a successful organization should be in dynamic learning (Zhang et al., 2009). Organizational learning is a process in which the organization continuously puts exposed to criticism and questions their product of process and existing systems and explains strategic position to applied different patterns and to achieve sustainable competitive results. Having a competitive advantage depends on the features of each organization, but certainly, the organization's staff and their knowledge have a decisive role in this pathway. In other words, learning is the main source of competitive advantage. Learning is for change another words learning in any organizational also should be convert to change and positive change and habit and become to organizational goals (Serajzadeh Esfahani, 2011). From a systematic approach can be said organizational learning is a dynamic concept that gradually changes from individual learning to organizational learning (Ouksel \& Vyhmeister, 2000). Learning culture encourages interaction, cooperation, curiosity and meditation and internal and external borders and effective of learning infrastructure. Learning infrastructures of ways of organizing resources and opportunities of strengthen meditation and partnerships, provides objective Learning culture and makes it capable for continued growth. Developing a culture of 
organizational learning is required to establish clear organizational goals, culture of participation and the relationship among organizational subsystems of structure and culture (Preskill \& Torres, 1999). Learning system has features which can achieve new prospects for the establishment of a participatory system to find solutions for complex social and administrative problems in changing societies. This system has emerged as a new "paradigm" of management. The new method can solve organizational problems in today's unstable environments that changing all variables such as values and expectations of community (Javanmard \& Sakha'ii, 2009). The following is an organizational learning process,

1. Acquire knowledge: Learning occurs when an organization to acquire the necessary knowledge. Acquire knowledge or facts and information is done through control environment, the use of information systems to save information, recycling information, research, implementation, education etc.

2. Information distribution: In this process, organizations will share information in different units and individuals.

3. Interpretation of information: In order for information to be used jointly, it should be analyzed and interpreted, properly.

4. Organizational memory: Organizational memory refers to the repository in which knowledge is stored for future use and many factors are involved in the creation of organizational memory (HeydariTafreshi et al., 2002; Garvin, 1993; Haber, 1991). Therefore, organizations that are focused on organizational learning culture (OCL) must first gain information then interpret the information to understand and finally convert the information to knowledge. Organizations should not forget very important part of behavioral and cognitive changes (Škerlavaj et al., 2010). Considering the above views, organizational learning features include complex process, not planned, conscious and purposeful, interactive and dynamic, continuous, evolving and growing, influenced by knowing foundation. However, it should be noted that today's companies are faced with challenges, which are largely related to organizational learning. It includes growing shortage of skills, knowledge doubling every two to three years, Global competition with the world's most powerful companies and organizations, Re-design and reconstruction of organizations, comprehensive development of new technology and advanced, be complex need of organizations to adapt to change. Despite the challenges, facing of today's organizations is critical action regarding the process of emotional intelligence to improve performance and more growth (Jamalzadeh et al, 2009). Therefore, learning is essential for success and development of organization. If there is no learn, the organization will face heavy cost of duplication and inefficiency and waste of resources and skills. To use of competitive advantage in organizations applied financial skills, marketing and technology are used to be successful in the competition (Yousefi Seahgourabi, 2010).

\section{Review of Literature}

So far, much research has been done about measuring emotional intelligence and its dimensions and its relationship to other variables. Lopez- Sanchez et al. (2011) designed and distributed a questionnaire among 181 medium-sized productive companies in Spain and reported that organizational learning affects on flexibility, competitive strategy and performance of a company. The results showed that organizational learning offers a major instrument in modern markets for customer value and makes possible improvement on organizational performance by using the effective design of competitive strategy and flexibility consistent with the rapid development of the market. Sun jung and Hyun Yoon (2011) studied the effects of emotional intelligence on counter productive work behaviors and organizational citizenship behavior among employees of restaurant (food and drink) in a luxury hotel in South Korea. Results showed that three factors of use of emotion and others emotion appraisal and appraisal self emotion had significant negative effect on Counter productive work behaviors and also appraisal self-emotion and use of emotion between emotional 
intelligence of employees had significant positive effect on organizational citizenship behaviors. Yarmohammadian and Sharafi Rad (2011) investigated the relationship between emotional intelligence and social adjustment in adolescent boys of high and guidance school in the town of Fasa. Results showed that strengthening emotional intelligence could be effective in social skills training and social adjustment of adolescents. Jahanian (2010) studied the relationship between emotional intelligence and conflict management in high schools in Tehran and reported that there was a significant relationship between emotional intelligence and conflict management. Škerlavaj et al. (2010) studied organizational learning culture, creativity culture and innovation in companies in South Korea. Results showed that organizational learning culture had a very strong direct and positive effect on innovation and also had relatively positive and indirect effect through an innovative culture on innovation. Teymournezhad and Sarehi (2010) investigated the effects of organizational learning on psychological empowerment in headquarters employees of the Ministry of Economic Affairs and Finance. Results showed that organizational learning is effective on the dimensions of psychological empowerment and can be a basis for formulating appropriate strategies of human resources in the field of organizational learning and psychological empowerment of employees.

HefferNan et al. (2008) studied the effects of managers' emotional intelligence and trust on bank performance. Results showed that there was a significant correlation between components of emotional intelligence and trust. Rezayian and Keshthgar (2008) in a research paid to study the relationship between emotional intelligence and organizational commitment among Maskan bank employees. Results showed that emotional intelligence had a significant relationship with organizational commitment of employees. Between the dimensions of emotional intelligence (emotional self-awareness, self management, social awareness and relationship management), relationship management showed the most influence on organizational commitment too. Sharifi and Eslamieh, (2008) investigated the relationship between organizational learning and application of ICT in Islamic Azad University of Garmsar and reported a significant relationship and direct and positive correlation between organizational learning and applying information and communication technologies at the University Garmsar. Adyemo (2007) studied the effect of adjuster of emotional intelligence on organizational commitment. Results showed that emotional intelligence has a significant effect on organizational commitment. Zahrakar (2007) studied the components of emotional intelligence and educational performance among all students of Islamic Azad University in Slamshahr. Results showed positive correlation between all the components of emotional intelligence and educational performance, also the results indicated that are significant predictors for educational performance among the components of emotional intelligence, optimism components, satisfaction, stress tolerance, impulse control and problem-solving. Dong and Howard (2006) studied emotional intelligence and job satisfaction and sense of trust on employees of the University of California. The results showed that there was a relationship between emotional intelligence and job satisfaction and also emotional intelligence can predict job satisfaction. Lopes - Paulo et al. (2003) studied emotional intelligence, personality and perceived quality of social relations in United States of America. Results showed that both of emotional intelligence and personality traits in their same time relation had reported the satisfaction of social relations.

\section{The proposed study}

The primary objective of this survey is to study the effects of emotional intelligence on organizational learning in staff of Jihad Agriculture Organization of Isfahan province. More specifically, we look for the following objectives,

1) Study the effect of self-awareness of staff on their organizational learning in the Jihad Agriculture Organization of Isfahan,

2) Study the effect of emotional management of staff on their organizational learning in the Jihad Agriculture Organization of Isfahan,

3) Study the effect of spontaneous of staff on their organizational learning in the Jihad Agriculture Organization of Isfahan, 
4) Study the effect of optimal communications of staff on their organizational learning in the Jihad Agriculture Organization of Isfahan,

5) Study the effect of direction to emotions of staff on their organizational learning in the Jihad Agriculture Organization of Isfahan.

\section{The hypotheses of research}

The main hypothesis is "Emotional intelligence of staff has a positive and significant effect on their organizational learning" and there are five sub-hypothesis as follows,

1) Self-awareness has a positive and significant effect on their organizational learning.

2) Emotional management of staff has a positive and significant effect on their organizational learning.

3) Spontaneous of staff has a positive and significant effect on their organizational learning.

4) Optimal communications of staff has a positive and significant effect on their organizational learning.

5) Direction to emotions of staff has a positive and significant effect on their organizational learning.

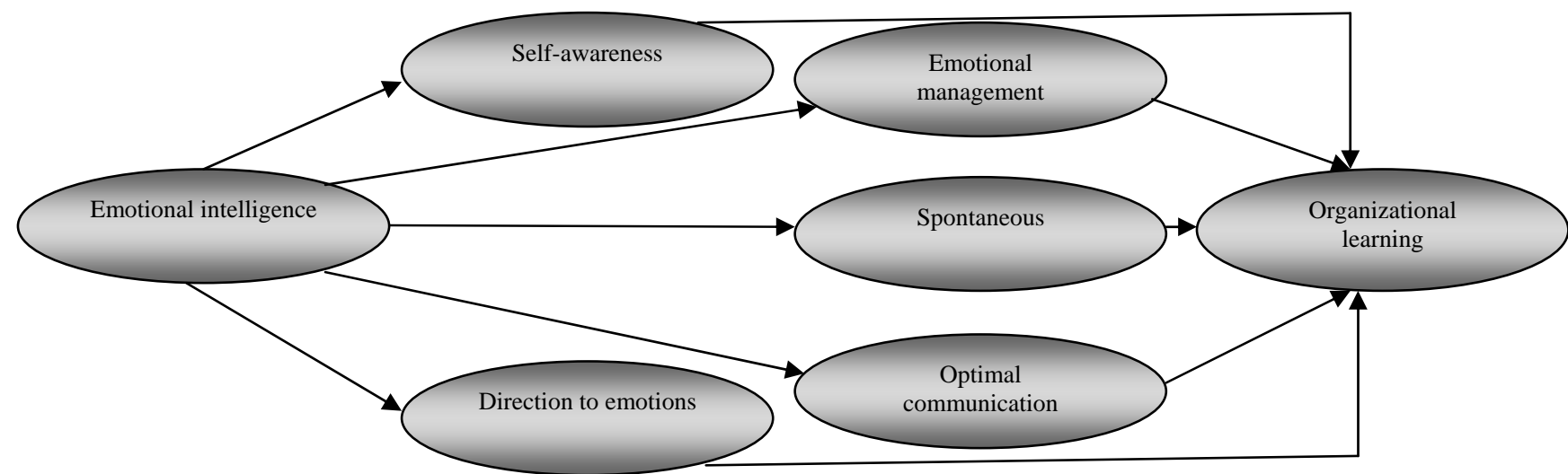

Fig. 1. The proposed model

\section{Research methodology}

The proposed study of this paper collects the necessary data using Weisinger's emotional intelligence questionnaire (2000), which includes 45 questions and the researcher made questionnaire on organizational learning was includes 16 questions and a group of university professors confirmed validity of the questionnaire.

\section{Table 1}

Sub hypotheses

\begin{tabular}{lccccc}
\hline \multirow{2}{*}{ The assumptions } & \multicolumn{4}{c}{ Hypotheses } \\
\cline { 2 - 6 } & Hypothes1 & Hypothes2 & Hypothes3 & Hypothes4 & Hypothes5 \\
\hline Coefficient of & Pearson & Pearson & Pearson & Pearson & Pearson \\
\multicolumn{1}{c}{ Type of Relationship } & Linear & Linear & Linear & Linear & Linear \\
Std. Error & 0.01 & 0.01 & 0.01 & 0.01 & 0.01 \\
$\mathrm{~N}$ & 217 & 217 & 217 & 217 & 217 \\
$\mathrm{R}$ & 0.550 & 0.500 & 0.656 & 0.717 & 0.651 \\
$\mathrm{R}^{2}$ & 0.302 & 0.25 & 0.43 & 0.514 & 0.423 \\
value-P & 0.000 & 0.000 & 0.000 & 0.000 & 0.000 \\
Sig & 0.99 & 0.99 & 0.99 & 0.99 & 0.99 \\
Hypothesis Verification & $\mathrm{H}_{1}$ & $\mathrm{H}_{1}$ & $\mathrm{H}_{1}$ & $\mathrm{H}_{1}$ & $\mathrm{H}_{1}$ \\
\hline
\end{tabular}

To determine the reliability of the questionnaire Cronbach alpha has been used and different factors of questionnaires are $0.835,0.837,0.824,0.850$ and 0.809 for emotional intelligence including selfawareness, emotional measurement, spontaneous, optional communication and direction to emotions, respectively. In addition, Cronbach's alpha is 0.786 for organizational learning and 0.864 for total 
factor, respectively. As we can observe, all calculated Cronbach alpha are well above the minimum acceptable level. Finally, the collect information to calculate variables research was stored in a database such as Excel (field method). Statistical data analysis was used based on the Pearson correlation and to test the main hypothesis stepwise regression has been used. The statistical population includes 500 people who worked for staff of Jihad Agriculture Organization of Isfahan province. Statistical population sample size yielded 217 using the Morgan statistical table for a period of 6 months of second half of 2011.

Table 2

Stepwise regression analysis

\begin{tabular}{ccccc}
\hline hypothesis & & & & \\
Type of regression & Step Wise & Step Wise & Step Wise & Step Wise \\
\hline Steps & Step1 & Step2 & Step3 & Step4 \\
Std. Error & 0.01 & 0.01 & 0.01 & 0.01 \\
$\mathrm{~N}$ & 217 & 217 & 217 & 0.866 \\
$\mathrm{R}$ & 0.717 & 0.850 & 0.863 & 0.750 \\
$\mathrm{R}^{2}$ & 0.514 & 0.723 & 0.745 & 0.746 \\
$\overline{\mathrm{R}}^{2}$ & 0.512 & 0.720 & 0.742 & 159.336 \\
$\mathrm{~F}$ & 227.201 & 278.624 & 207.864 & 0.000 \\
value-P & 0.0000 & 0.000 & 0.000 & 0.99 \\
Sig & 0.99 & 0.99 & 0.99 & $\mathrm{H}_{1}$ \\
\hline Hypothesis Verification & $\mathrm{H}_{1}$ & $\mathrm{H}_{1}$ & $\mathrm{H}_{1}$ & \\
\hline
\end{tabular}

1. The result of hypothesis no 1 indicates that there is a meaningful relationship between selfawareness and organizational learning in the Jihad Agriculture Organization of Isfahan when the level of significance is 0.000 and acceptable error level of \%1.

2. The result of hypothesis no 2 indicates that there is a meaningful relationship between emotional management and organizational learning in the Jihad Agriculture Organization of Isfahan when the level of significance is 0.000 and acceptable error level of \%1.

3. The result of hypothesis no 3 indicates that there is a meaningful relationship between spontaneous and organizational learning in the Jihad Agriculture Organization of Isfahan when the level of significance is 0.000 and acceptable error level of $\% 1$.

4. The result of hypothesis no 4 indicates that there is a meaningful relationship between optimal communications and organizational learning in the Jihad Agriculture Organization of Isfahan when the level of significance is 0.000 and acceptable error level of $\% 1$.

5. The result of hypothesis no 5 indicates that there is a meaningful relationship between direction to emotions and organizational learning in the Jihad Agriculture Organization of when the level of significance is 0.000 and acceptable error level of $\% 1$.

6. The main hypothesis specifies that emotional intelligence of staff positively impact on their organizational learning. As we have already explained, we performed stepwise regression and the regression model used four variables in four steps. All statistical observations maintain meaningful results when the level of significance is 1 percent. The model describes approximately 75 percent of the changes of dependent variable. In summary, emotional intelligence influences organizational learning in this organization.

\section{Conclusion}

The results of this survey have shown that there is a significant relationship between emotional intelligence and organizational learning. Thus, emotional intelligence is one of the most important factors, which must be measured in this organization. The importance of this subject becomes more apparent when organization requires for change to make an assessment on strengths and weaknesses of the workforce. In addition, among different dimensions of emotional intelligence, optimal communication, awareness and spontaneous maintain the highest impact on organizational learning. In addition, the results demonstrated that the optimal communication receives the highest importance in emotional intelligence and impacts the most on organizational learning. As Rezayian and Keshthgar (2008), Yarmohammadian (2011) and Lopez- Sanchez (2011) also in their findings 
showed that relationships management and optimal communication are the most important variables of emotional intelligence. Optimal communication skills play an important role in successfully person job. The study performed on hiring officials in 2007 showed they thought that communication skills is the most important characteristic of an ideal job applicant's (Robbins \& Jaj, 2010). In order to improve optimal communication people require skills such as self openness, courage, effective listening and team communication. Thus, human resource managers should put their agenda seriously educational topics on this issue. This point is also important that strengthen communication and staff relationships with others in the formal and informal groups will cause of increased feelings and emotions and also increasing of emotional allegiances among them. Optimal communication is worthwhile effect in creating emotional cohesion among staff and finally provides stronger sense of collaboration and cooperation among them. In addition, the results showed that self-awareness is the second important variable of emotional intelligence, which impacts on organizational learning. People who have greater self-awareness create a better picture of specific location in their minds and have more willing to choose a job matched with their needs, values and interests. Self-awareness enables people to react faster than their surroundings signs and learn more from their environment. Also the spontaneous was recognized the third important variable of emotional intelligence and due to the importance that motivation has for doing things, create conditions to motivate people in their work path play a great role in doing something right by them and their learning. Generally, a result of this study and other studies have been done on emotional intelligence. (Zahrakar, 2007; Jahanean, 2010; Dong \& Howard, 2006; Adimu, 2007; Hafernan, 2008) showed importance and its role as an organizational behavior which improves the variables of organizational learning, organizational performance, conflict management, job satisfaction, organizational commitment, organizational trust and finally organizational effectiveness. Therefore, education for improving emotional intelligence can have positive effects on individual performance and consequently organization. Accordingly, part of human resource strategies should be focused on appropriate education about how to control and improve emotional intelligence and organizational learning capabilities of staff.

\section{References}

Adeyemo, D.A. (2007). Emotional Intelligence and the relationship between job satisfaction and organizational commitment of employee in public parastatals oyo state Nigeria. Pakistan Journal of social sciences. 4(2), 324-330.

Besharat, M. A. (2005). Study the effect of emotional intelligence on the quality of social life. Psychological Studies, 1(2), 25-38.

Beirami, M. Gharibi, H., Hashemi, T., \& Gholizadeh, Z. (2010). Predicting students' emotional intelligence based on demographic factors. Applied Psychology, 4(14), 57-64.

Dong, Q., \& Howard, T.M. (2006). Emotional intelligence trust and job satisfaction. Competition Forum, 4(2), 381-388.

Feizi, T., \& Abedini, S. (2010). The relationship between emotional intelligence and social capital (case study). Journal of Economics and Business, 1(1), 43-57.

Gharibi Varzaqani, F. (2011). Management of emotional intelligence at schools. Educational Technology of Growth, 3(27), 32-35.

Garvin, D. A. (1993). Building a learning organization. Harvard Business Review, 3, 78-91.

Ghassemzadeh Debgi, H. (2007). Mind, intelligence and mathematics education. Journal of Applied Mathematics of Lahijan, 4, 77-81.

Hedat, A. R. (2008). The effect of emotional intelligence on employee attitudes than Knowledge sharing in the Neroukler company. Thesis Master of Business Administration, University of Isfahan.

HeydariTafreshi, G, H., Yousefi, S. A. R., \& Khadivy, A. (2002). The new approach to organization and management theories in today's world. $1^{\text {st }}$ ed. Tehran, publisher Meta cognitive thought.

Heffernan, T., Onill, G., Tavaglione, T., \& Droulers, M. (2008). The impact of emotional intelligence and trust on bank performance. International Journal of bank marketing, 26(9), 183-199.

Jamalzadeh, M, Gholami, Y, \& Saif, M, H. (2009). The relationship between organizational intelligence and organizational learning between staff and faculty members between area 1 of Islamic Azad University and 
provide a model for promoting organizational learning. Journal of Educational and Management Leadership, 3(2), 63-86.

Javanmard, H. A., \& Sakha'ii, F. (2009). Relationship between interpersonal skills, organizational learning, innovation and organizational performance in small and medium industries in Markazi province. Journal of Insight, 16, 81-96.

Jahanian, R. (2010). Study the relationship between emotional intelligence and conflict management in managers. Journal of Management, 8, 1-8.

Lopes, P. N., Salovey, P., \& Straus, R. (2003). Emotional intelligence, personality, and the perceived quality of social relationships. Personality and Individual Differences, 35, 641- 658.

Lopez-Sanchez, J.A., Santos-Vijande, M.L., \& Trespalacios, J.A. (2011). How organizational learning affects a firm's flexibility, competitive strategy, and performance. Journal of Business Research, 65(8), 11.

Mohrman, S.A., Galbraith,J.R., \& Lawler III, E.E. (1998). Tomorrow's organization: Crafting winning capabilities in a dynamic world, Jossey-Bass Business \& Management.

Nazem, F. (2008). Organizational learning at Islamic Azad University. The Journal of New Ideas in Educational Sciences, 3(4), 23-11.

Nasrollahpour, K. (2007). The effect of emotional intelligence and soliloquy on strategies for confrontation with stress in Shiraz University students. MS Thesis of Shiraz University.

Ostvar, S., \& Amirzade Khatouni, M. (2008). Investigate the relationship between emotional intelligence, job satisfaction and organizational commitment in factory workers of the private sector in the city of Shiraz . Journal of new approach in Educational Management, 1(2), 23-38.

Ouksel, A, \& Vyhmeister, R. (2000). Performance of organizational design models and their impact on organization learning. Journal of Computational \&Mathematical Organization Theory, 6(4), 395-410.

Perkhaefi, A, R., Manavipour, D., \& Pashashrifi, H. (2010). Comparison of creativity and intelligence of students in different fields. Journal of New ideas in Education, 3(1).

Preskill, H., \& Torres, R. T. (1999). The Role of Evaluative Enquiry in Creating Learning Organization. Organizational learning and the learning organization, London: Sage.

Robbins, S, \& Judge, T. J. (2010). Organizational behavior. Pearson Education, $13^{\text {th }}$ edition

Rezayian, A, \& Keshthgar, A. A. (2008). The relationship between emotional intelligence and organizational commitment. Message of Management, 27, 27-39.

Senge, P. M. (1999). The Dance of Change: The Challenges to Sustaining Momentum in Learning Organizations ( $1^{\text {st }}$ ed.). New York: Currency/Doubleday.

Serajzadeh Esfahani, M. (2011). The relationship between servant leadership and organizational learning in Iran Power Plant Projects Management Company. Master's thesis of Industrial Management, Islamic Azad University of Najaf Abad.

Sharifi, A., \& Eslamieh, F. (2008). Investigate the relationship between organizational learning and applying information and communication technologies at Islamic Azad University of Garmsar in the 2007-2008 academic year. Quarterly Journal of New Approaches in Educational Administration, Islamic Azad University of Marvdasht, 1(2), 1-22.

Soltani, I. (2008). Self-assessment tools and improvements in knowledge management at human resource management. $1^{\text {st }}$ ed., published by Tehran's knowledge bases.

Škerlavaj, M., Song, J.H., \& Lee, Y. (2010). Organizational learning culture, innovative culture and innovations in South Korean firms. Expert Systems with Applications, 37(3), 6390- 6403.

Sun Jung, H., \& Hyun Yoon, H.(2011). The effects of emotional intelligence on counterproductive work behaviors and organizational citizen behaviors among food and beverage employees in a deluxe hotel. International Journal of Hospitality Management, 32(12), 1- 10.

Teymournezhad, K., \& Sarehi Sfastani, R. (2010). The effects of organizational learning on psychological empowerment in headquarters employees of the Ministry of Economic Affairs and Finance. Journal of Management improvement and development Studies, 62, 59-37.

Yarmohammadian, A., \& Sharafi Rad, H. (2011). Analysis of the relationship between emotional intelligence and social adjustment in adolescent boys. Journal of Urban and Regional Studies and Research, 2(8).

Yousefi Syahgourabi, M. (2010). Organizational learning. bimonthly Development Engineering Futures of Market Developers.

Zahrakar, K. (2007). Investigate the relationship components of emotional intelligence and educational performance. Journal of Applied Psychology, 2(5), 89-98.

Zhang, L., Tian, Y., \& Qi, Z. (2009). A conceptual model of organizational learning based on knowledge sharing. Sixth International Conference on Advanced Learning Technologies (ICALT'06), 20(5), 4 -6. 